\title{
Overcompensation in response to simulated herbivory in the perennial herb Sedum maximum
}

\author{
Paweł Olejniczak
}

Received: 1 July 2010/ Accepted: 15 September 2010/Published online: 9 October 2011

(C) The Author(s) 2011. This article is published with open access at Springerlink.com

\begin{abstract}
A positive effect of herbivory on plant reproduction (overcompensation) has been documented mostly in monocarpic plants. Iteroparous perennials can be used to test whether enhanced reproduction in 1 year has negative future consequences as predicted by optimal allocation models. This study was intended to verify this prediction in the iteroparous herb Sedum maximum, applying mechanically simulated herbivory. I monitored 132 labelled $S$. maximum individuals during 2 years of study. They were randomly assigned to two groups: clipped and control. Infructescence dry mass, total seed dry mass, seed size, germination rate and an increase of root dry mass during the season were assessed in the experimental plants. Since only roots can survive to the next season, root dry mass was considered a reliable measure of allocation to future performance. Clipped plants showed increased fruit and seed dry mass versus the controls, with no other aspect of reproduction affected. Apical bud removal also had a positive effect on increase of root dry mass. The results indicate true overcompensation in response to simulated herbivory with no future costs of increased reproduction. Moreover, increased plant reproduction as a result of herbivory is likely to persist in the following years: clipping increased not only seed production but also
\end{abstract}

P. Olejniczak ( $\square)$

Institute of Nature Conservation, Polish Academy of Science, Mickiewicza 33, 31-120 Kraków, Poland e-mail: olejniczak@iop.krakow.pl root growth. This response is inconsistent with the results of optimal allocation models and the discrepancy is probably due to violation of the resource limitation assumption. Plants adapted to tolerate herbivory seem not to reproduce at the maximum rate when undamaged, but rather withhold resources to be allocated to reproduction after herbivory.

Keywords Costs of reproduction · Herbivory tolerance $\cdot$ Plant-herbivore interactions $\cdot$ Resource allocation

\section{Introduction}

Herbivores can substantially affect plant populations by removing considerable amounts of plant biomass in both terrestrial (McNaughton 1989) and aquatic ecosystems (Cyr and Pace 1993). Herbivores are viewed as one of the most important selective forces in plant populations and plants have responded by evolving various defence mechanisms as adaptations against herbivory (Agrawal 2000). One such adaptation is tolerance, the ability of plants to regrow and reproduce to reduce the negative effects of herbivore damage. The degree of tolerance to herbivory varies between species (Hawkes and Sullivan 2001), populations (Lennartsson et al. 1997) and families (Agrawal et al. 1999). If a damaged plant has the same fitness as its undamaged relative, then it is said to compensate fully for herbivory. In some cases the fitness of plants 
damaged by herbivores may be even higher than the fitness of undamaged plants. Such a situation is referred to as overcompensation. Here I will use this term only in the context of enhancement of plant reproduction and not other aspects of plant performance such as vegetative growth or biomass, which are not necessarily related to reproductive success.

Herbivory is traditionally classified as an interspecific interaction that is beneficial to one organism, the herbivore, and harmful to another, the plant. Unless some other indirect effects are invoked (e.g. de Mazancourt et al. 2001), herbivory is bound to be harmful to a plant because it deprives the plant of a certain portion of resources. In spite of this, overcompensation has been documented a number of times (e.g. Paige and Whitham 1987; Lowenberg 1994; Lennartsson et al. 1997; Agrawal et al. 1999). The first evidence of overcompensation provoked controversy about the possibility of mutualistic relationships between plants and herbivores. For example, Bergelson and Crawley (1992) and Bergelson et al. (1996) criticized the suggestion by Paige and Whitham (1987) that the herb Ipomopsis aggregata may benefit from its ungulate herbivores, and attributed their finding of benefits to methodological limitations. However, more recent studies in different experimental designs in this (Paige 1999) and other systems (Lennartsson et al. 1998; Rautio et al. 2005) provide more solid support for overcompensation. According to Järemo et al. (1999), differences in fitness definitions may account for the apparent discrepancy between the existence of overcompensation and the fact that plants cannot benefit directly from their consumers. They suggest that the risk of herbivore encounters reduces mean fitness in a plant population but may still increase the absolute fitness of a phenotype.

The possibility of a positive effect of herbivory on plant performance has gained additional support from theoretical considerations. The earliest models (van der Meijden 1990; Vail 1992) assume a constant resource pool that can be partitioned into seed production before or after herbivory. Greater seed production after herbivory is expected when the probability of herbivory is sufficiently high (van der Meijden 1990; Vail 1992) or when herbivores exhibit a relatively high preference for intensively reproducing plants (Vail 1992). It is also postulated that herbivory tolerance should depend on environmental factors. The concept of compensatory continuum predicts that overcompensation should be observed in resource-rich environments (Maschinski and Whitham 1989) because such conditions provide a higher potential for plant regrowth. The possibility of overcompensation is also predicted by models assuming bud dormancy as adaptation to apical meristem loss from, for example, herbivory (Tuomi et al. 1994; Nilsson et al. 1996). Overcompensation is more likely when a higher proportion of buds remains dormant, which is favored under a high risk of herbivory and when herbivores remove a large fraction of meristems per plant (Tuomi et al. 1994). Focusing on bud dormancy produces predictions on the dependence of herbivory tolerance on the resource level that are inconsistent with the compensatory continuum hypothesis (Maschinski and Whitham 1989). If herbivory triggers the growth of dormant buds, then the response should be more likely under higher competition and in low-resource environments. Under highresource conditions, plants exhibit more branched architecture by preserving fewer dormant buds, which results in lower herbivory tolerance (Rautio et al. 2005). Wise and Abrahamson (2005) attempted to unify these different approaches, proposing a model differentiating between resources that limit plant fitness and those that are affected by herbivores.

In spite of all the work on overcompensation, the research is incomplete and some areas are not covered. All the above models were constructed for monocarps. The empirical evidence of overcompensation mostly concerns plants with a single bout of seed production (Paige and Whitham 1987; Lowenberg 1994; Lennartsson et al. 1997; Agrawal et al. 1999; Rautio et al. 2005), the reason being that comparing reproductive output of grazed plants with that of non-grazed plants is relatively straightforward in monocarps. The aim of this study was to examine whether overcompensation in terms of current and future performance can be observed in iteroparous perennial plants. In such plants studying the effect of herbivory on plant reproduction within a single year (e.g. Hicks and Turkington 2000; Gao et al. 2008) is insufficient to decide on the effect of herbivores on plant fitness, as it may entail many reproductive events. Here I present the results of a field experiment on the short- and longterm effects of artificial bud removal on the rate of reproduction of a perennial herb, Sedum maximum. If reproduction of a perennial plant is enhanced in a given year as a result of clipping, then the classical 
allocation models predict that the plant will reach a reduced size and hence achieve reduced future reproductive performance (Kozlowski and Uchmanski 1987; Pugliese 1988; Iwasa and Cohen 1989; Pugliese and Kozlowski 1990). In contrast, models of herbivory (van der Meijden 1990; Vail 1992; Tuomi et al. 1994; Nilsson et al. 1996; Lehtilä 2000) give grounds for predicting positive lifetime effects of clipping. This study was intended to provide empirical data to distinguish between these two possible outcomes of apical bud removal in perennial herbs.

\section{Materials and methods}

\section{Study species}

S. maximum L. (S. telephium ssp. maximum Koch) (Crassulaceae) is an iteroparous perennial herb widely distributed in Eurasia. Dormant buds survive winter beneath or at the soil level. In spring, buds start to grow and produce upright, usually unbranched shoots. In August, an inflorescence is produced at the top of the shoot. Fruits with many seeds $0.5-1.5 \mathrm{~mm}$ long are formed at the end of the growing season. At more or less the same time, nutrients are withdrawn from the shoot and leaves, the leaves fall, and the dried shoot remains, supporting an infructescence. The fruit capsules crack and release wind-dispersed seeds. The mother plant overwinters as a root forming a cluster of 5-30 tuberous finger-like root units. No runners, stolons or any other structures for vegetative reproduction were recorded at the experimental sites, so I based the reproductive success estimates on the plant's investment in seeds.

S. maximum grows on calciferous high-pH soils. It often occurs in xerothermic grassland and can tolerate drought and high temperature. It is exposed to herbivory from mammals, snails and insects, including caterpillars of the apollo butterfly (Parnassius apollo), a specialist herbivore. The herbivores often remove the top part of the shoot: as a result, the shoot branches and may produce more than one inflorescence.

\section{Study area}

The experiment was conducted in the Pieniny Mts in Southern Poland $\left(49^{\circ} 25^{\prime} \mathrm{N}, 20^{\circ} 21^{\prime} \mathrm{E}\right)$. The Pieniny Mts are a narrow range formed mostly on limestone rocks with steep south-facing walls. Stony debris accumulated at the wall bases serves as a habitat for $S$. maximum. The habitat is characterized by relatively sparse vegetation and minimal above-ground interference from other plants (personal observations). Growing between unstable stones, S. maximum is constantly faced with a risk of slides, root exposure and desiccation. As a response to this $S$. maximum evolved outstanding resilience to root excavation, which made it especially suitable for the study that involves repeated below-ground biomass assessment.

The Pieniny Mts harbour a large population of the apollo butterfly, a specialist herbivore for S. maximum. After a drastic decline between 1960 and 1990 (Witkowski et al. 1997), the population has been successfully restored to ca. 1000 mature individuals currently inhabiting an area of about 40 ha of a suitable habitat (Adamski and Witkowski 2007). Reports on the status of the population dating to the middle of 19-th century (Adamski and Witkowski 2007) indicate that the apollo butterfly was much more abundant then. Caterpillars of the apollo butterfly feed on the apical parts of shoots and younger leaves of $S$. maximum. Other common herbivores that damage the upper part of the shoot are cervid ungulates and the caterpillars of some moth species of the family Tortricidae (Adamski et al. 2000).

Experimental procedure

In April and May 2002, when the S. maximum shoots started to emerge, I measured the shoots and then excavated, weighed and labelled the plants, replanting each one at its original site. I measured the diameter of the shoot at the base to an accuracy of $0.1 \mathrm{~mm}$ using a standard calliper. Individuals whose shoot diameter was less than $1.8 \mathrm{~mm}$ or more than $3.6 \mathrm{~mm}$ were excluded from the experimental group, because the smallest individuals may not have reached maturity, and the largest were likely to produce more than one generative shoot, which would have confounded interpretation of the results. The roots of plants were gently brushed to remove the soil before weighing with a spring balance (Pesola AG, Baar, Switzerland) to the nearest $0.1 \mathrm{~g}$. Then, 2-3 weeks after the initial measurement, individuals were randomly assigned to experimental treatments: about half of them had their shoots clipped, the others left intact as a control. To mimic natural herbivory damage from caterpillars, 
clipping removed the apical bud together with the top third of the shoot. All experimental plants were monitored through the growing season every ca. 4 weeks to assess the timing and causes of mortality, natural herbivory in the population and the timing of flowering.

In November, when the fruits matured I collected the infructescences, excavated the experimental plants and weighed their roots. Infructescences were weighed and the seeds were shaken out of the capsules and weighed. The seeds were placed on a transparent plastic screen and scanned to a bitmap file. Seed number and size were assessed on the bitmap with image analysis software (analySIS, Soft Imaging System GmbH, Münster, Germany). Germination frequency was measured in random samples of 50 seeds from each individual, 5 and 15 days after sowing on a moist towel.

Parallel to the measurements of experimental plants, every time the roots of experimental plants were weighed I sampled six roots of non-experimental plants and measured their water content (drying at $110^{\circ} \mathrm{C}$ to constant weight, electronic drying balance, RADWAG, Radom, Poland). Water content was used as a correction term to calculate the estimated dry mass of roots weighed on a given day. The procedure applied to roots excavated at the beginning and then at the end of the growing season enabled estimation of dry root biomass increase through the season. Dry root biomass increase is an alternative to allocation to seeds and was treated as investment in future reproductive success.

The whole procedure was repeated in the next year and the plants examined in that year constituted a second cohort. In April 2003, I also made a census of the first cohort. Only a fraction of the individuals had their buds emerged, so I was able to relate the probability of early emergence to the root weight at the end of the previous season. This would indicate whether root size has an effect on the performance of $S$. maximum in the following year.

In the 2 years of the experiment, 303 S. maximum plants were labelled and followed in the experiment (233 first year, 1970s year). Some of them had to be withdrawn from the experimental groups for one of the following reasons: damage to roots from excavation or soil removal was so severe that further manipulation was abandoned (18 plants); shoots suffered from drought later in the course of the experiment (13 plants); a parasitic plant, dodder (Cuscuta sp.), substantially reduced growth and flowering (28 plants); or the root was exposed by rock slides or drenching (6 plants).

Statistical analysis

All statistical analyses employed SPSS ver. 11.0 (SPSS, Chicago, Ill.). The relationship between the probability of early emergence of $S$. maximum buds and the dry root mass at the end of the previous season was tested using logistic regression. The relationship between experimental treatment and number of inflorescences was analysed by means of a $G$ test of a $2 \times 2$ table with the number of inflorescences categorized into two groups (equal to 1, equal to 2 or more). The effect of experimental apical bud removal on flowering time was analysed with Fisher's exact test, because the minority of plants flowered before August and all the rest started flowering before the next census, making the expected counts in two cells of the $2 \times 2$ frequency table less than 5. Other effects of experimental apical bud removal were tested by two-way ANCOVA with treatment group and cohort used as factors. The natural logarithm of initial dry root weight was used as a covariate to control for the possible effect of initial plant size. Infructescence dry mass and total seed dry mass were log-transformed before analyses to achieve homogeneity of error variances and to make the allometric relationship between the dependent variable and the covariate linear (Cheplick 2005).

Individuals that had their apical buds removed by natural herbivory at any time of the season were excluded from testing all the effects of clipping to avoid non-random effects of uncontrolled bud removal. When the collected infructescence of an individual was incomplete, it was excluded from the analyses of the effects of clipping on total fruit weight and on total seed weight. All quantitative-trait measurements were made by the same person.

\section{Results}

Characteristics of experimental plants

Herbivores caused apical bud damage to 106 of the 303 marked individuals. This means that more than a third of the population experiences a natural abscission of the apical bud. There was no relationship between natural herbivory and treatment ( $G$ test, 
$G=2.805, d f=1, \mathrm{NS}$ ), indicating that herbivores did not show any preference for clipped or control S. maximum plants. I followed 132 individuals to the end of the growing season and determined their final status. The data on these individuals were used to test the hypotheses of this study.

There were no initial size differences between clipped and control individuals as checked by comparison of initial root dry mass (two-way ANOVA effect of treatment, $F_{1,128}=0.004$, NS; treatment $\times$ cohort interaction, $\left.F_{1,128}=1.395, \mathrm{NS}\right)$. Of the 58 first-cohort individuals that were located in early spring of the following year, 23 had already emerged. Early emergence probability correlated positively with dry root mass at the end of the preceding year (logistic regression, $B=0.436, \mathrm{SE}=$ $0.160, P<0.01)$.

\section{Effects of clipping}

Apical bud removal had positive effects on infructescence dry mass (Fig. 1a) and on total seed dry mass (Fig. 1b) in $S$. maximum. Damage to the shoot, intended to imitate herbivory, stimulated higher fruit and seed production, as clipped plants produced more shoot branches with inflorescences than the controls ( $G$ test, $G=100.49, d f=1, P<0.001$ ). Clipping also had a positive effect on the seasonal increase of dry root mass (Fig. 1c). There were no negative effects of clipping on other examined S. maximum characteristics, such as germination rate or seed size (Table 1). All the responses were consistent in the two cohorts, as shown by the non-significance of interaction effects. Nor were there cost of damage expressed as delayed reproduction of damaged plants: flowering time did not differ between clipped and control plants (Fisher's exact test, $P=0.634$ ). These results indicate that individuals with their apical buds removed allocated more resources into current reproduction and at the same time invested more in future performance than undamaged individuals did. This response, with no accompanying costs detected, should be regarded as overcompensation.

\section{Discussion}

The experiment revealed a positive effect of apical bud removal (artificial abscission) on reproductive
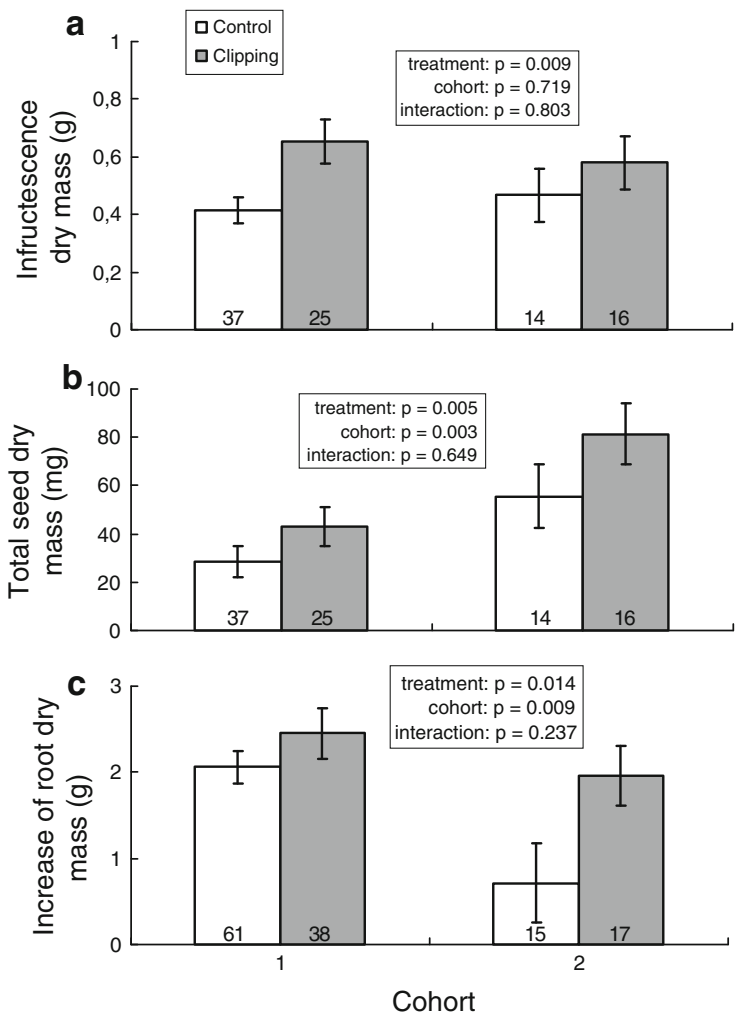

Fig. 1 Effects of clipping and cohort on a infructescence dry mass, $\mathbf{b}$ total seed dry mass and $\mathbf{c}$ seasonal increase in root dry mass. Plots display $P$-values for each effect (ANCOVA). Natural logarithm of initial root dry mass was used as a covariate. Numbers of individuals used in the analyses are provided in the bars. Error bars denote means $\pm \mathrm{SE}$

success in $S$. maximum. This is the first report of overcompensation in an iteroparous perennial plant in which future costs of herbivore-induced reproduction are explicitly measured. Previously, this phenomenon was known in monocarpic plants such as Ipomopsis aggregata (Paige and Whitham 1987), Sanicula arctopoides (Lowenberg 1994), Gentianella campestris (Lennartsson et al. 1997), Raphanus raphanistrum (Agrawal et al. 1999) and Erysimum strictum (Rautio et al. 2005). Studies on iteroparous perennials that report a positive effect of herbivores on plant reproduction are usually based on the data from a single growing season and overlook future consequences of enhanced reproduction (Hicks and Turkington 2000; Gao et al. 2008). Canto et al. (2004) conducted their defoliating experiment on iteroparous Anthurium schlechtendalii in two consecutive years. However, the consequences of increased reproduction in the first 
Table 1 Results of full factorial two-way ANCOVAs

\begin{tabular}{|c|c|c|c|c|c|}
\hline Dependent variable & Source of variation & $d f$ & MS & $F$ & $P$ \\
\hline \multirow[t]{5}{*}{ Germination at day 5} & Covariate & 1 & 0.005 & 0.277 & 0.600 \\
\hline & Treatment & 1 & 0.005 & 0.291 & 0.591 \\
\hline & Cohort & 1 & 0.000 & 0.007 & 0.933 \\
\hline & Treatment $\times$ cohort & 1 & 0.023 & 1.261 & 0.264 \\
\hline & Error & 96 & 0.018 & & \\
\hline \multirow[t]{5}{*}{ Germination at day 15} & Covariate & 1 & 0.018 & 0.215 & 0.644 \\
\hline & Treatment & 1 & 0.007 & 0.084 & 0.772 \\
\hline & Cohort & 1 & 2.420 & 28.929 & 0.000 \\
\hline & Treatment $\times$ cohort & 1 & 0.150 & 1.791 & 0.184 \\
\hline & Error & 96 & 0.084 & & \\
\hline \multirow[t]{5}{*}{ Mean seed length } & Covariate & 1 & 0.023 & 1.192 & 0.278 \\
\hline & Treatment & 1 & 0.009 & 0.463 & 0.498 \\
\hline & Cohort & 1 & 0.004 & 0.186 & 0.667 \\
\hline & Treatment $\times$ cohort & 1 & 0.035 & 1.779 & 0.185 \\
\hline & Error & 95 & 0.020 & & \\
\hline \multirow[t]{5}{*}{ Mean seed projection area } & Covariate & 1 & 0.005 & 1.275 & 0.262 \\
\hline & Treatment & 1 & 0.000 & 0.128 & 0.721 \\
\hline & Cohort & 1 & 0.001 & 0.321 & 0.572 \\
\hline & Treatment $\times$ cohort & 1 & 0.004 & 1.390 & 0.241 \\
\hline & Error & 95 & & & \\
\hline
\end{tabular}

The effects of clipping (treatment) and cohort on the fraction of germinating seeds 5 and 15 days after sowing, on mean seed length per plant and mean seed projection area per plant are shown. Natural logarithm of initial root dry mass was used as a covariate

year were obscured because the plants were defoliated also in the subsequent year, which made it impossible to separate the effects of both treatments. Nevertheless, the authors interpret their results in terms of allocation trade-off and conclude that high short-term inflorescence production in A. schlechtendalii may have a long-term negative impact on fitness. In $S$. maximum apical bud removal induced higher reproduction in a year of treatment; this effect is likely to persist in the future, as organs that overwinter, that is, the roots also grow bigger. Other studies designed to reveal effects of simulated herbivory on polycarpic herbs in more than one growing season failed to show positive effects of the damage on the overall plant reproductive performance (Venecz and Aarssen 1998; Huhta et al. 2009).

The property of $S$. maximum that made this experiment possible was its enormous ability to withstand excavation of the roots. In this study, I estimated the risk of naturally caused root exposure at $2 \%$ per year; this may be sufficient selection pressure to evolve such an ability in the perennial species.
Moreover, if the negative effect of the root exposure is mediated by insufficient water supply, then $S$. maximum is particularly equipped to overcome this. In this species, a water deficit shifts photosynthetic metabolism to the crassulacean acid metabolism (CAM) pathway, substantially reducing daytime water loss (Lee and Griffiths 1987; Borland 1996).

The results of the experiment might still have been affected by the apparently strong effect of the initial manipulation. It is hard to imagine that excavating the roots has no consequences for the plant, but only a small proportion $(6 \%)$ of the experimental plants suffered substantially from the manipulation. Unearthing the below-ground parts is likely to cause damage to fibrous roots, but in this study the magnitude of the effect is independent of the treatment because the plants were randomly assigned to experimental groups following the initial manipulation. Accidental detachment of the fibrous roots might result in underestimation of plant biomass at the beginning of the growing season. The tuberous roots of $S$. maximum are fairly easy to excavate completely and their biomass seems a 
good approximation starting biomass as they are material stored for spring regrowth. The relative allocation of biomass to fibrous and storage roots has not been studied in $S$. maximum, and the only reports come from agricultural plants such as carrot (Hole and Dearman 1991), usually selected for increased storage root fraction. A drought-tolerant cultivar of sugar beet showed a higher tap root/fibrous root dry weight ratio than a drought-intolerant cultivar (Shaw et al. 2002), suggesting that ignoring some fibrous root losses in a xeromorphic $S$. maximum would not substantially affect the results.

To control better for the amount of the tissue removed in the experiment and for the timing of damage, I used mechanical clipping as the trigger for herbivory tolerance responses. Mechanical damage rarely mimics natural herbivory exactly (Baldwin 1990). Unlike clipping, damage from herbivores induces the expression of genes potentially involved in defence (Reymond et al. 2004). If the induced defence is costly, then the reproductive performance of clipped plants may be more than the reproduction of naturally browsed plants as they are expected to allocate some resources to defence. However, such a pattern has not been discovered in studies in which overcompensation was induced both by natural and mechanical damage. In Ipomopsis aggregata, none of the nine investigated fitness measures was significantly higher in plants subjected to simulated herbivory (Paige and Whitham 1987); on the contrary, the mean values of most of them were slightly in favour of naturally browsed plants. In $R$. raphanistrum, overcompensation was not found to be more frequent among clipped siblings (Agrawal et al. 1999), even though natural herbivory was observed to induce efficient resistance mechanisms (Agrawal 1998). Using natural herbivores is therefore not likely to reduce the chance of revealing the positive effect of plant damage in the experiment, particularly since overcompensation in $S$. maximum is mediated by increased shoot branching, and this response, releasing auxiliary bud dormancy, is fairly conservative regardless of the mode of apical bud removal (Leyser 2003).

It should be noted that not all individuals of the investigated populations were candidates for the experimental groups. The smallest and largest ones were not included into the experiment, so the finding of positive effect of clipping on S. maximum reproductive performance is not universal. In order to make the results more generally applicable, however, I did not restricted the experimental groups to single-sized individuals, as Lennartsson et al. (1998) did, but tried to use individuals from a range of initial sizes and then to control for individual size, using it as a covariate in the statistical analyses. Paige (1999) took the same approach in another study on overcompensation.

Simulated herbivory resulted in higher average fruit and seed production by damaged $S$. maximum individuals. This positive effect of clipping on reproduction during the year of manipulation was accompanied by enhanced future performance: higher increase of root dry mass. Root dry mass at the end of the growing season accounts almost entirely for plant size in this species and plant size at the end of the season has often been reported to be a good indicator of future reproduction (e.g. Schmid et al. 1995; Piqueras 1999; Mendez and Karlsson 2004). My results also show that greater root dry mass at the end of a season increases the probability of early emergence in the next spring, which is also expected to correlate with higher fitness (Verdu and Traveset 2005). The simultaneous increase of current and future reproduction without an increase of available resources (removing the apex even cuts off resources) contradicts lifehistory allocation models. Allocation models assume resource limitation, which leads to management of resources in such a way that investing more in one activity inevitably results in reduced allocation to another (trade off). Thus, it seems that the reproduction rate of intact $S$. maximum individuals is not limited by resources. Undamaged plants do not reproduce maximally and, as suggested by Agrawal (2000), they may restrain full reproduction until after herbivory. Herbivory would provide a cue that the risk has passed (van der Meijden 1990), but even when the repeated grazing is considered, overcompensation after herbivory may be favoured (Nilsson et al. 1996).

Overcompensation in response to herbivory may still seem controversial because of the apparent positive effect of the damage. The discrepancy between the intuitive assumption that herbivores cannot benefit the browsed plant and some contradictory empirical results may be reconciled by viewing the costs of herbivory on an evolutionary time scale. If one imagines naïve plants that have not evolved under herbivory, then an adaptation to herbivore damage would constitute the cost, as the fitness of the adapted plants is lower than that of naïve ones regardless of 
whether the adapted plants have been browsed or not (Tuomi et al. 1994). The conclusion of a positive effect of herbivory should not be based on comparison of the fitness of a damaged plant with that of an intact one, because these two cases represent possible outcomes of a single conditional strategy. The fitness of the strategy should be treated jointly as an average of the two possibilities weighted by the risk of herbivore encounter. If the probability of being browsed is high enough to make the weighted average of adapted plants greater than the weighted average of naïve ones, then tolerance to herbivory is expected to evolve (van der Meijden 1990). Overcompensation is one particular outcome of such evolution, albeit an extreme one.

Acknowledgments I am grateful to P. Adamski and $\mathrm{Z}$. Witkowski for introducing me into the study system and the administration of Pieniny National Park for allowing to conduct the research. I thank all who helped in collecting the data, especially K. Olejniczak, P. Adamski, A. Delimat, M. Hus, I. Nieścior, M. Śmiałek and BISC students. J. Fyda helped with image analysis software licensed to INoŚ UJ. K. Vrieling, M. Czarnołęski and J. Toumi improved the manuscript with their discussions and comments. This research was partly supported by KBN grant no. 3 P04F 08222.

Open Access This article is distributed under the terms of the Creative Commons Attribution Noncommercial License which permits any noncommercial use, distribution, and reproduction in any medium, provided the original author(s) and source are credited.

\section{References}

Adamski P, Witkowski ZJ (2007) Effectiveness of population recovery projects based on captive breeding. Biol Conserv 140:1-7

Adamski P, Margielewska K, Witkowski Z (2000) Compensation and induced defence in response to herbivory in Sedum maximum (Crassulaceae). Fragm Florist Geobot 45: 193-202

Agrawal AA (1998) Induced responses to herbivory and increased plant performance. Science 279:1201-1202

Agrawal AA (2000) Overcompensation of plants in response to herbivory and the by-product benefits of mutualism. Trends Plant Sci 5:309-313

Agrawal AA, Strauss SY, Stout MJ (1999) Costs of induced responses and tolerance to herbivory in male and female fitness components of wild radish. Evolution 53:10931104

Baldwin IT (1990) Herbivory simulations in ecological research. Trends Ecol Evol 5:91-93

Bergelson J, Crawley MJ (1992) Herbivory and Ipomopsis aggregata: the disadvantages of being eaten. Am Nat 139: $870-882$
Bergelson J, Juenger T, Crawley MJ (1996) Regrowth following herbivory in Ipomopsis aggregata: compensation but not overcompensation. Am Nat 148:744-755

Borland AM (1996) A model for the partitioning of photosynthetically fixed carbon during the C-3-CAM transition in Sedum telephium. New Phytol 134:433-444

Canto A, Parra-Tabla V, Garcia-Franco G (2004) Variations in leaf production and floral display of Anthurium schlechtendalii (Araceae) in response to herbivory and environment. Funct Ecol 18:692-699

Cheplick G (2005) The allometry of reproductive allocation. In: Reekie E, Bazzaz F (eds) Reproductive allocation in plants. Elsevier Academic Press, San Diego, pp 97-128

Cyr H, Pace ML (1993) Magnitude and patterns of herbivory in aquatic and terrestrial ecosystems. Nature 361:148-150

de Mazancourt C, Loreau M, Dieckmann U (2001) Can the evolution of plant defense lead to plant-herbivore mutualism? Am Nat 158:109-123

Gao Y, Wang D, Ba L, Bai Y, Liu B (2008) Interactions between herbivory and resource availability on grazing tolerance of Leymus chinensis. Environ Exp Bot 63:113-122

Hawkes CV, Sullivan JJ (2001) The impact of herbivory on plants in different resource conditions: a meta-analysis. Ecology 82:2045-2058

Hicks S, Turkington R (2000) Compensatory growth of three herbaceous perennial species: the effects of clipping and nutrient availability. Can J Bot 78:759-767

Hole CC, Dearman J (1991) Carbon economy of carrots during initiation of the storage root in cultivars contrasting in shoot-root ratio at maturity. Annals Bot 68:427-434

Huhta A-P, Rautio P, Hellstrom K, Saari M, Tuomi J (2009) Tolerance of a perennial herb Pimpinella saxifraga to simulated flower herbivory and grazing: immediate repair of injury or postponed reproduction? Plant Ecol 201: 599-609

Iwasa Y, Cohen D (1989) Optimal growth schedule of a perennial plant. Am Nat 133:480-505

Järemo J, Tuomi J, Nilsson P, Lennartsson T (1999) Plant adaptations to herbivory: mutualistic versus antagonistic coevolution. Oikos 84:313-320

Kozlowski J, Uchmanski J (1987) Optimal individual growth and reproduction in perennial species with indeterminate growth. Evol Ecol 1:214-230

Lee HSJ, Griffiths H (1987) Induction and repression of CAM in Sedum telephium $\mathrm{L}$. in response to photoperiod and waterstress. J Exp Bot 38:834-841

Lehtilä K (2000) Modelling compensatory regrowth with bud dormancy and gradual activation of buds. Evol Ecol 14: 315-330

Lennartsson T, Tuomi J, Nilsson P (1997) Evidence for an evolutionary history of overcompensation in the grassland biennial Gentianella campestris (Gentianaceae). Am Nat 149:1147-1155

Lennartsson T, Nilsson P, Tuomi J (1998) Induction of overcompensation in the field gentian Gentianella campestris. Ecology 79:1061-1072

Leyser O (2003) Regulation of shoot branching by auxin. Trends Plant Sci 8:541-545

Lowenberg GJ (1994) Effects of floral herbivory on maternal reproduction in Sanicula arctopoides (Apiaceae). Ecology 75:359-369 
Maschinski J, Whitham TG (1989) The continuum of plant responses to herbivory: the influence of plant association nutrient availability and timing. Am Nat 134:1-19

McNaughton SJ (1989) Ecosystem-level patterns of primary productivity and herbivory in terrestrial habitats. Nature 341:142-144

Mendez M, Karlsson PS (2004) Between-population variation in size-dependent reproduction and reproductive allocation in Pinguicula vulgaris (Lentibulariaceae) and its environmental correlates. Oikos 104:59-70

Nilsson P, Tuomi J, Åström M (1996) Even repeated grazing may select for overcompensation. Ecology 77:1942-1946

Paige KN (1999) Regrowth following ungulate herbivory in Ipomopsis aggregata: geographic evidence for overcompensation. Oecologia 118:316-323

Paige KN, Whitham TG (1987) Overcompensation in response to mammalian herbivory: the advantage of being eaten. Am Nat 129:407-416

Piqueras J (1999) Herbivory and ramet performance in the clonal herb Trientalis europea L. J Ecol 87:450-460

Pugliese A (1988) Optimal resource allocation in perennial plants: a continuous-time model. Theor Popul Biol 34: 215-247

Pugliese A, Kozlowski J (1990) Optimal patterns of growth and reproduction for perennial plants with persisting or not persisting vegetative parts. Evol Ecol 4:75-89

Rautio P, Huhta AP, Piippo S, Tuomi J, Juenger T, Saari M, Aspi J (2005) Overcompensation and adaptive plasticity of apical dominance in Erysimum strictum (Brassicaceae) in response to simulated browsing and resource availability. Oikos 111:179-191
Reymond P, Bodenhausen N, Van Poecke RMP, Krishnamurthy V, Dicke M, Farmer EE (2004) A conserved transcript pattern in response to a specialist and a generalist herbivore. Plant Cell 16:3132-3147

Schmid B, Bazzaz FA, Weiner J (1995) Size dependency of sexual reproduction and of clonal growth in two perennial plants. Can J Bot 73:1831-1837

Shaw B, Thomas TH, Cooke DT (2002) Responses of sugar beet (Beta vulgaris L.) to drought and nutrient deficiency stress. Plant Growth Regul 37:77-83

Tuomi J, Nilsson P, Åström M (1994) Plant compensatory responses: bud dormancy as an adaptation to herbivory. Ecology 75:1429-1436

Vail SG (1992) Selection for overcompensatory plant responses to herbivory: a mechanism for the evolution of plant-herbivore mutualism. Am Nat 139:1-8

van der Meijden E (1990) Herbivory as a trigger for growth. Funct Ecol 4:597-598

Venecz JI, Aarssen LW (1998) Effects of shoot apex removal in Lythrum salicaria (Lythraceae): assessing the costs of reproduction and apical dominance. Ann Bot Fenn 35: 101-111

Verdu M, Traveset A (2005) Early emergence enhances plant fitness: a phylogenetically controlled meta-analysis. Ecology 86:1385-1394

Wise MJ, Abrahamson WG (2005) Beyond the compensatory continuum: environmental resource levels and plant tolerance to herbivory. Oikos 109:417-428

Witkowski Z, Adamski P, Kosior A, Plonka P (1997) Extinction and reintroduction of Parnassius apollo in the Pieniny National Park (Polish Carpathians). Biologia 52:199-208 